\title{
Declining trend in mortality after myocardial infarction
}

\author{
ANDERS Å BERG, ROBERT BERGSTRAND, SAGA JOHANSSON, GÖRAN ULVENSTAM, \\ ANDERS VEDIN, HANS WEDEL, CLAES WILHELMSSON, LARS WILHELMSEN
}

From the Section of Preventive Cardiology, Department of Medicine, Ostra Hospital, Göteborg, Sweden

SUMMARY All patients under 60 years of age who were discharged from hospital after a first myocardial infarction between 1968 and 1977 in Göteborg were followed for a minimum of 24 months. The patients were unselected, and treatment was standardised. The patients were divided into five two yearly cohorts, and the prognostic comparability and mortality of these cohorts were assessed. There was a reduction in the two year mortality rate after discharge during the 10 year period. Small baseline differences between the cohorts were controlled by multivariate methods, and a subsequent analysis showed that there was a declining trend in mortality between 1968 and 1977. A higher tendency among smokers to give up smoking and a lower prevalence of angina pectoris could explain only part of the reduction in mortality. A small number of patients underwent a coronary bypass operation; the slight increase in the number of operations during the period cannot, however, account for the reduced mortality. Most of the patients in the later cohorts were treated with beta blockers, and this is the most likely explanation for the majority of the decline in mortality.

During the past decade the mortality due to coronary heart disease has declined in some Western countries. ${ }^{1-3}$ Changes in cardiovascular risk factors and improved medical care in the community have been proposed as explanations for this trend,,$^{1-3}$ as has improved care during admission to hospital. 4

The mortality after myocardial infarction accounts for about a third of the total coronary heart disease mortality. During the past decade there have been several studies of the effects of different secondary preventive measures such as cessation of smoking and long term beta blockade. ${ }^{56}$ Despite growing interest in secondary prevention it has been difficult to show any reduction in mortality after discharge from hospital among larger groups of patients. ${ }^{7-10}$ In Göteborg, all patients in the middle-aged groups have been routinely followed up after myocardial infarction since 1968.

We undertook this study, firstly, to investigate whether there was a change in mortality after myocardial infarction over the 10 year period and, secondly, to find explanations for any such change.

Requests for reprints to Dr Anders Äberg, Section of Preventive Cardiology, Department of Medicine, Ostra Hospital, S-416 85 Göteborg, Sweden.

Accepted for publication 6 September 1983

\section{Patients and methods}

Since 1 January 1968 all cases of myocardial infarction occurring in Göteborg have been recorded by the Myocardial Infarction Register. ${ }^{11}$ The present study comprised men and women who had had a first myocardial infarction and were selected as follows: for the two years $1968-69$ all patients aged $\leqslant 55$ years; for the two years $1970-71$ all patients aged $\leqslant 59$ years (except a random 30\% sample of those aged 57-59 years who formed a reference group); for 1972 every other patient $<60$ years; and for 1973 up to 31 December 1977 all patients $<60$ years. Thus a total of 1322 patients who survived until discharge from hospital were studied (Table 1).

\section{QUESTIONNAIRES}

After discharge the patients were treated according to a uniform regimen agreed at regular staff meetings. Physical examinations were undertaken at intervals dictated by the patients' clinical condition and always at one, three, 12, and 24 months after infarction. ${ }^{12}$ Patients who were not able to visit the clinic were offered new appointments, and patients who had moved to other areas were encouraged to fill in questionnaires sent to them. For all interviews and physical examinations identical questionnaires were completed by the same investigators. The form for the period of hospital stay contained questions about 
Table 1 Age and sex distribution of 1322 patients with a first myocardial infarction discharged from hospital (1968-77). Figures are numbers of patients

\begin{tabular}{lrcr}
\hline Age $(y r)$ & Men & Women & Total \\
\hline$<34$ & 14 & 2 & 16 \\
$35-39$ & 25 & 5 & 30 \\
$40-44$ & 83 & 13 & 96 \\
$45-49$ & 196 & 28 & 224 \\
$50-54$ & 374 & 70 & 444 \\
$55-59$ & 421 & 91 & 512 \\
Total & 1113 & 209 & 1322 \\
\hline
\end{tabular}

demographic details and previous diseases, cardiovascular and respiratory symptoms, smoking habits, amount of physical activity undertaken at work and during leisure, and clinical condition at the onset of the disease, during hospital admission, and at discharge. The form for completion at follow up examinations contained questions about cardiovascular and respiratory symptoms, smoking habits, complications, certain diseases, clinical condition, and laboratory data. ${ }^{12}$

For recording dyspnoea and chest pain on exertion the questionnaire devised by Rose and Blackburn was used. ${ }^{13}$ All patients who had dyspnoea or chest pain when climbing a small hill or walking rapidly on level ground or on less exertion were recorded as having dyspnoea or chest pain on exertion. Previously diagnosed hypertension and diabetes were recorded if present. With regard to chest pain and dyspnoea at the onset of myocardial infarction, the patient's statement at the first interview was used. Left ventricular failure during hospital admission was considered to exist when basal pulmonary rales or increased prominence of pulmonary vessels on $x$ ray films were noted more often than occasionally in the patient's records. Other conditions, such as atrial fibrillation, were considered to have occurred if they had been recorded at any time during admission. Blood samples for determining serum transaminase activity (serum aspartate transaminase and serum alanine transaminase) were collected on three consecutive days according to a special standardised schedule.

Patients who smoked at least one cigarette, or the equivalent amount of tobacco, each day or who had stopped smoking less than three months before infarction were classified as smokers. Patients who had never smoked or who had smoked continuously for less than a month were defined as non-smokers. Other patients were regarded as ex-smokers. The patients who stopped smoking after infarction and were still non-smokers three months after the myocardial infarction were regarded as having stopped smoking.

MANAGEMENT

All patients were informed about the association bet- ween smoking and ischaemic heart disease. The smokers were advised to stop smoking. Persisting hypertension during the follow up period was treated with a beta blocker or a diuretic or a combination of both. General dietary information was given to the patients during admission for myocardial infarction and also at the postmyocardial infarction clinic. When the serum cholesterol concentration was $7.8 \mathrm{mmol} / \mathrm{l}$ $(300 \mathrm{mg} / \mathrm{dl})$ or higher specific dietary advice was given, sometimes by a dietitian, and a lipid reducing agent prescribed, both at the discretion of the physician. Treatment with lipid reducing agents never exceeded $8 \%$ in the highest cholesterol quintile among the patients in the study.

Treatment during follow up was otherwise based on formalised criteria. In 1975 the findings of several trials of beta blockade were adopted, and alprenolol was given routinely to all patients in whom beta blockade was not contraindicated.

\section{MORTALITY DATA}

Mortality was established by the Myocardial Infarction Register by continuous checking of all national death certificates. ${ }^{11}$ Death certificates for all inhabitants of Göteborg were sent to the Myocardial Infarction Register, even if the death occurred outside the city or abroad. In a small number of patients who moved from Göteborg during the follow up period the death certificates issued in the new city or county were routinely checked at the three month, 12 month, and 24 month examinations. In this study all causes of mortality were analysed. As a further check on survi$\mathrm{val}$, patients who failed to keep their appointment at the postmyocardial infarction clinic were followed up.

All the patients in this study were followed for 24 months. In this study they were divided into five two yearly cohorts from 1968 to 1977 . The total mortality and the levels of primary and secondary risk factors were analysed for these five cohorts.

\section{STATISTICAL METHODS}

The extensions of Mantel-Haenszel's procedure were used to test the linear trend of survival curves through the years 1968 to $1977 . .^{14} 15$ The occurrence of and values of variables recorded during the acute stage of myocardial infarction (dyspnoea, left ventricular failure, atrial flutter or fibrillation, peak serum aspartate transaminase concentrations, and relative heart vol$u_{m} e^{162}$ ) were recorded according to standard criteria throughout the study period. These factors were used together as a prognotic index in a multiple logistic model. ${ }^{16 \mathrm{~b}}$ The Cox proportional hazard model was used to analyse the trend after adjusting for factors previously shown to be of prognostic importance for mortality after myocardial infarction. ${ }^{17}$ Thus in addition to the prognostic index, age and date of infarction 
were used as covariates in the Cox model. The date of infarction was transformed to a decimal character in order to be used as a continuous variable in the Cox analysis-that is, a person with an acute myocardial infarction on 1 July 1976 was given the value 76.50. In the presentation of the results we have used discrete periods of two years for simplicity. Two tail tests were used and $p$ values $<0.05$ were considered to be significant.

\section{Results}

Table 1 shows the age distribution of the 1113 men and 209 women included in the study.

The prognostic comparability of the different two yearly cohorts was assessed. Table 2 shows the patients' characteristics before infarction. The prevalence of angina pectoris before infarction decreased from nearly $50 \%$ in the first cohort to just over $30 \%$ in the last cohort $(p=0.0006)$. The percentage of smokers at the time of infarction decreased from $92 \%$ in the first cohort to $72 \%$ in the last $(p=0.018)$. No such trend was found for the other variables.

Table 3 shows the variables recorded during hospital admission. For methodological reasons the patients in the first cohort were younger. The mean peak serum aspartate transaminase activity and the frequency of atrial arrhythmias decreased during the 10 year period $(p=0.0005$ and $p=0.035)$, but the other variables remained stable. During admission digitalis was given less frequently $(p=0.12)$ and diuretics more frequently $(\mathrm{p}<0.0001)$.
Table 4 Variables of secondary prognostic importance recorded three months after myocardial infarction in 1322 patients with a first myocardial infarction who were later discharged from hospital (1968-77)

\begin{tabular}{lll}
\hline Cohort & $\begin{array}{l}\text { Smokers who } \\
\text { stopped smoking } \\
(\%)\end{array}$ & $\begin{array}{l}\text { Patients treated with } \\
\text { beta blockers } \\
(\%)\end{array}$ \\
\hline $1968-69$ & 47 & 4 \\
$1970-71$ & 56 & 10 \\
$1972-73$ & 53 & 16 \\
$1974-75$ & 51 & 54 \\
$1976-77$ & 65 & 70 \\
\hline
\end{tabular}

Table 5 Mortality after 24 months in 1322 patients with first myocardial infarction who were later discharged from hospital (1968-77)

\begin{tabular}{lllll}
\hline Cohorts & $\begin{array}{l}\text { No of } \\
\text { patients }\end{array}$ & $\begin{array}{l}\text { No of } \\
\text { deaths }\end{array}$ & $\begin{array}{l}\text { Mortality } \\
\text { rate (\%) }\end{array}$ & $\begin{array}{l}\text { Confidence } \\
\text { intervals (\%) }\end{array}$ \\
\hline $1968-69$ & 173 & 25 & $14 \cdot 5$ & $9 \cdot 3-21$ \\
$1970-71$ & 311 & 22 & $7 \cdot 1$ & $4 \cdot 6-11 \cdot 3$ \\
$1972-73$ & 248 & 27 & $10 \cdot 9$ & $7 \cdot 2-15 \cdot 4$ \\
$1974-75$ & 324 & 26 & $8 \cdot 0$ & $5 \cdot 2-12.5$ \\
$1976-77$ & 266 & 17 & $6 \cdot 4$ & $3 \cdot 7-10.7$ \\
\hline
\end{tabular}

Table 4 shows the percentage of smokers who stopped smoking and that of patients who were treated with beta blockers in the different cohorts. More smokers stopped smoking $(p=0.025)$, and more patients were treated with beta blockers $(p<0.0001)$ in the later cohorts.

Among all patients there was a total of 117 deaths after discharge from hospital during the first 24 months of follow up. Table 5 shows the crude mortal-

Table 2 Characteristics before infarction of 1322 patients with a first myocardial infarction who were later discharged from hospital (1968-77)

\begin{tabular}{|c|c|c|c|c|c|c|c|}
\hline Cohort & $\begin{array}{l}\text { Total } \\
\text { No }\end{array}$ & $\begin{array}{l}\text { Women } \\
(\%)\end{array}$ & $\begin{array}{l}\text { Smokers } \\
(\%)\end{array}$ & $\begin{array}{l}\text { Angina pectoris } \\
(\%)\end{array}$ & $\begin{array}{l}\text { Hypertension } \\
(\%)\end{array}$ & $\begin{array}{l}\text { Diabetes } \\
(\%)\end{array}$ & $\begin{array}{l}\text { Digitalis } \\
\text { treatment } \\
(\%)\end{array}$ \\
\hline $\begin{array}{l}1968-69 \\
1970-71 \\
1972-73 \\
1974-75 \\
1976-77\end{array}$ & $\begin{array}{l}173 \\
311 \\
248 \\
324 \\
266\end{array}$ & $\begin{array}{l}10 \\
18 \\
15 \\
19 \\
16\end{array}$ & $\begin{array}{l}92 \\
81 \\
79 \\
76 \\
72\end{array}$ & $\begin{array}{l}48 \\
41 \\
42 \\
36 \\
33\end{array}$ & $\begin{array}{l}24 \\
26 \\
20 \\
28 \\
23\end{array}$ & $\begin{array}{l}8 \\
5 \\
5 \\
7 \\
5\end{array}$ & $\begin{array}{l}4 \\
4 \\
4 \\
8 \\
6\end{array}$ \\
\hline
\end{tabular}

Table 3 Clinical details recorded during hospital admission of 1322 patients with a first myocardial infarction who were later discharged (1968-77)

\begin{tabular}{|c|c|c|c|c|c|c|c|c|c|}
\hline \multirow{2}{*}{$\begin{array}{l}\text { Cohort } \\
\\
1968-69 \\
1970-71 \\
1972-73 \\
1974-75 \\
1976-77\end{array}$} & \multirow{2}{*}{$\begin{array}{l}\text { Total No } \\
173 \\
311 \\
248 \\
324 \\
266\end{array}$} & \multirow{2}{*}{$\begin{array}{l}\begin{array}{l}\text { Mean age } \\
(y r)\end{array} \\
49.6 \\
52.2 \\
52.7 \\
51.8 \\
52.4\end{array}$} & \multirow{2}{*}{$\begin{array}{l}\begin{array}{l}\text { Dyspnoea on } \\
\text { infarction } \\
(\%)\end{array} \\
38 \\
32 \\
34 \\
34 \\
33\end{array}$} & \multirow{2}{*}{$\begin{array}{l}\text { Left ventricular } \\
\text { failure } \\
(\%)\end{array}$} & \multirow{2}{*}{$\begin{array}{l}\begin{array}{l}\text { Atrial flutter/ } \\
\text { fibrillation } \\
\text { (\%) }\end{array} \\
10 \\
3 \\
0 \\
5 \\
3\end{array}$} & \multicolumn{2}{|c|}{$\begin{array}{l}\text { Mean }( \pm S D) \text { peak } \\
A S T \text { activity } \\
(\mu k a t / l)\end{array}$} & \multicolumn{2}{|c|}{$\begin{array}{l}\text { Mean }( \pm S D) \text { relative } \\
\text { heant volume } \\
\text { ( } \mathrm{ml} / \mathrm{m}^{2} \text { body surface area) }\end{array}$} \\
\hline & & & & & & $\begin{array}{l}3.3 \\
3.1 \\
2.8 \\
2.4 \\
2.7\end{array}$ & $\begin{array}{l}( \pm 2 \cdot 7) \\
( \pm 2 \cdot 7) \\
( \pm 2 \cdot 4) \\
( \pm 2 \cdot 1) \\
( \pm 2 \cdot 3)\end{array}$ & $\begin{array}{l}453 \\
457 \\
462 \\
463 \\
465\end{array}$ & $\begin{array}{l}( \pm 101 \cdot 0) \\
( \pm 94 \cdot 1) \\
( \pm 96.0) \\
( \pm 92 \cdot 6) \\
( \pm 108 \cdot 9)\end{array}$ \\
\hline
\end{tabular}

AST, aspartate transaminase. 


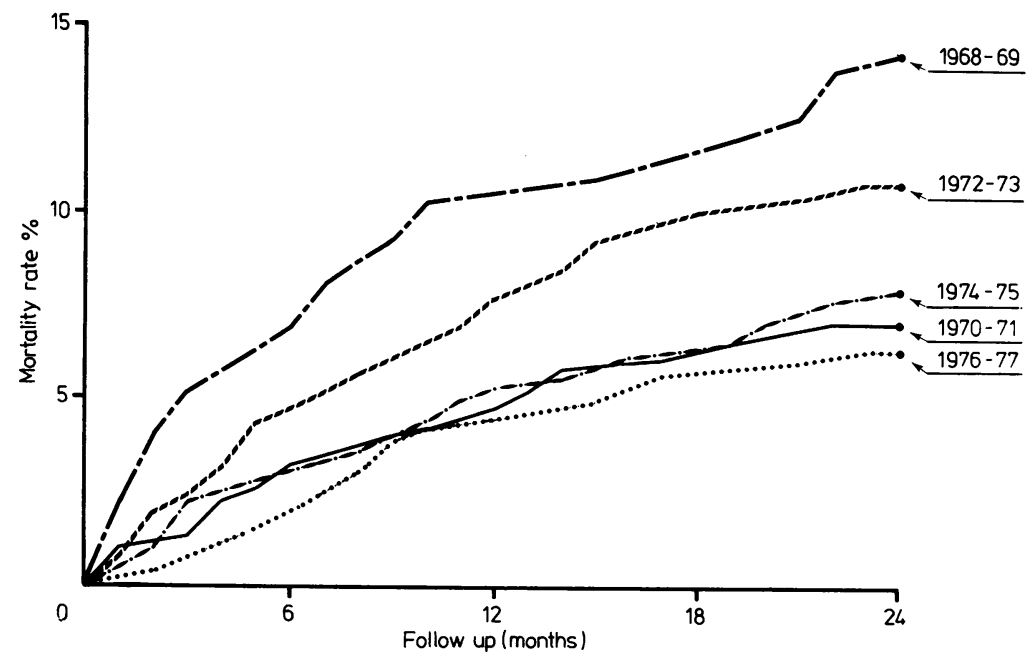

Fig. 1 Cumulative mortality rate for the different biannual cohorts of 1322 patients with a first myocardial infarction and discharged from hospital.

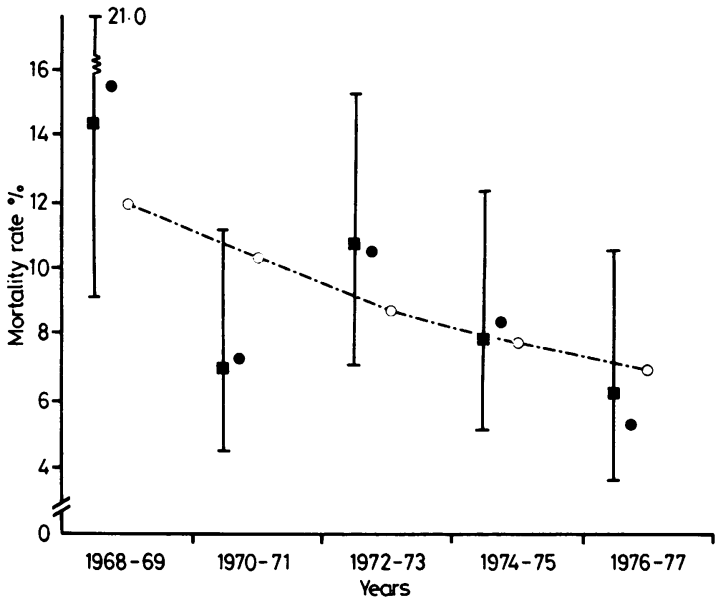

Fig. 2 Mortality rates after 24 months for 1322 patients with a first myocardial infarction who were discharged from hospital (1968-1977). ( $\square$-Crude rates with the $95 \%$ confidence intervals; (O) -rates adjusted for the mean age and prognosis; (O) -Cox smoothed regression curve adjusted for age and prognosis.

ity rate after 24 months for the five cohorts. Despite large variations between the cohorts there was a general decline in mortality rate $(p=0.029)$. Fig. 1 shows the cumulative mortality curves. The difference in mortality between the early and late cohorts was mainly due to a low mortality during the first three months in the later cohorts $(p=0.018)$.

Fig. 2 shows the different two year mortality rates for the five cohorts: the crude mortality rates as above, the mortality rates standardised to the mean age and prognosis of all patients, and the mortality estimated by the Cox model. The Cox analysis showed that mortality after discharge from hospital was still declining $(p<0.04)$ when adjusted for the expected prognosis and age.

\section{Discussion}

The patients in this study were unselected, and the methods used were standardised and unchanged throughout the follow up. ${ }^{12} 18$ The number of patients who could not be followed up was negligible. ${ }^{12}$ The reliability of end points (in this case deaths from various causes) had been assessed. 18

The different cohorts studied were comparable with regard to many of the characteristics before infarction, but there were some differences in the prevalence of angina pectoris and smoking habits. Perhaps the widespread use of beta blockers in the late 1970 s was the reason for the decreasing percentage of patients with angina pectoris before myocardial infarction. During the 10 year period the number of coronary bypass operations was less than $3 \%$ in any of the cohorts.

To compare the two year mortality rates after discharge from hospital for the different cohorts we standardised for factors of prognostic importance after myocardial infarction. ${ }^{16}$ In this study the declining mortality after infarction was independent of age and estimated probability of death within two years. It was also independent of the lower frequency of atrial arrhythmias. During the study less digitalis and more diuretics were used in the treatment of left ven- 
tricular failure, but this variable did not change during the study.

There may be several explanations for the decline in mortality. The total cardiovascular mortality in the Göteborg area was stable during the study period. ${ }^{19}$ This does not contradict the results in our study since the mortality after myocardial infarction is only a part of the cardiovascular mortality. Mortality before admission to hospital might have been increasing so that more patients died before admission and, therefore, did not influence the follow up mortality.

Hospital mortality probably decreased during the 1960s and 1970s because of the improved care offered by more coronary care units and the improved diagnosis and treatment of life threatening arrhythmias. ${ }^{20}$ The hospital mortality may also have decreased during the study period because the length of admission fell from about 19 days to about 11 days. The lower mortality in hospital due to the shorter stay would, however, tend to increase mortality later during the follow up period. The mortality trends after myocardial infarction have been standardised for factors reflecting the severity of infarction that predict mortality during this period. ${ }^{16}$

The primary cardiovascular risk factors might have been influenced by changes in life style, dietary habits, physical fitness, and perhaps a more aggressive approach to the detection and control of hypertension. This influence has been claimed to be the most important explanation for the decline in cardiovascular mortality in some Western countries. ${ }^{2}$ In Göteborg, there was a significant reduction in blood pressure levels, serum cholesterol values, and in the prevalence of smoking in the general population of men of 50 years old between 1970 and 1980 (L Wilhelmsen, unpublished data). These changes have not yet influenced the total cardiovascular mortality in Göteborg and are unlikely to influence the mortality rate during the relatively short period of two years, particularly after myocardial infarction when many other factors are important. ${ }^{21} 22$

A change in the selection of patients for admission to hospital could influence the mortality rate after myocardial infarction. The increase in the general awareness of symptoms of myocardial infarction may have resulted in patients with milder symptoms being admitted to hospital. This was not true, however, in this series, since there was no consistent increase in the number of patients admitted (Table 2). Furthermore, the Cox analysis would prevent such differences between cohorts influencing the results.

Smoking after myocardial infarction is well established as a powerful secondary risk factor. ${ }^{5}$ In this study there was an increase in the percentage of patients who stopped smoking. In previous studies of the effects of stopping smoking, this had only very limited effects on mortality during early follow up. ${ }^{23}$

There are now several studies of the relation between treatment with beta blockers after myocardial infarction and the reduction of deaths and non-fatal reinfarctions. ${ }^{624}$ The first of these studies, ${ }^{24}$ our own, was published in 1974 and led to a massive increase in the percentage of patients treated with beta blockers in the middle of the 1970s; in the last three cohorts up to nearly $70 \%$ of patients were treated. This could be a major contributory factor explaining the result. The effect of beta blockade could not be analysed more closely for several reasons. Firstly, because treatment with beta blockers in the early cohorts was restricted to patients with hypertension and angina pectoris and was rare-the numbers of patients and possible end points were too few. Secondly, in the last two cohorts most patients were treated with beta blockers. Those not treated cannot, however, be easily compared with those who were because they had contraindications for beta blockade-for example, severe cardiac failure, chronic bronchitis or asthma, or diabetes mellitus. Thus these patients would be heavily biased towards a bad prognosis even after adjustment with the prognostic model used.

Since the secular declining trend in mortality was particularly pronounced during the first three months these findings indicate an early effect of beta blockade. $^{6}$

A few studies suggest the possibility of a declining mortality after discharge from hospital.$^{8-1020}$ Hunt $e t$ al found a lower one year mortality rate after acute myocardial infarction later in the observation period. ${ }^{20}$ These workers also proposed beta blockade as an explanation. The findings of the other studies were, however, not conclusive. The latest study used a technique similar to the one in this study. ${ }^{10}$ In that study, however, the patients were included up to 12 months after myocardial infarction, ${ }^{10}$ and any differences in early mortality might easily have been missed. Furthermore, as judged from the report, treatment with beta blockers was not common in those patients.

The present study showed an encouraging decrease in mortality after myocardial infarction after discharge from hospital between 1968 and 1977. The reduction, which was independent of age and estimated risk, could not have been due solely to a change in smoking habits or to the prevalence of angina before infarction. The mortality in the later years was $28 \%$ lower than that in earlier years. The size of this reduction is comparable with that found in the major trials of beta blockers. ${ }^{6}$ As most patients were treated with beta blockers during these years a decline in mortality of this order would be predicted, and treatment with beta blockers is most likely to be the chief explanation. 


\section{References}

1 Stallones RA. The rise and fall of ischemic heart disease. Sci Am 1980; 243: 53-9.

2 Havlik RJ, Feinleib M, eds. Proceedings of the conference on the decline in coronary heart disease mortality. Washington, DC: Government Printing Office, 1979. (DHEW publication No. (NIH)79-1610.)

3 Feinleib M, Havlik RJ, Thom TJ. The changing pattern of ischemic heart disease. Fournal of Cardiovascular Medicine 1982; 7: 139-46.

4 Stern MP. The recent decline in ischemic heart disease mortality. Ann Intern Med 1979; 91: 630-40.

5 Åberg A, Bergstrand R, Johansson S, et al. Cessation of smoking after myocardial infarction. Effects of mortality after 10 years. Br Heart $\mathcal{F}$ 1983; 49: 416-22.

6 The Norwegian Multicenter Study Group. Timololinduced reductions in mortality and reinfarction in patients surviving acute myocardial infarction. $N$ Engl $\mathcal{F}$ Med 1981; 304: 801-7.

7 Isacsson S-O, Johansson BW. Myocardial infarction in Malmö during the 10-year period 1963-1972. Acta Med Scand 1979; 206: 293-8.

8 Goldberg R, Szklo M, Tonascia JA, Kennedy HL. Time trends in prognosis of patients with myocardial infarction: a population-based study. Fohns Hopkins Med $\mathcal{F}$ 1979; 144: 73-80.

9 Craig IH, Byrne E, Tiltman RCB. Changing mortality from ischaemic heart disease and acute myocardial infarction. Med f Aust 1978; 2: 461-4.

10 Weinblatt E, Goldberg JD, Ruberman W, Frank CW, Monk MA, Chandhary BS. Mortality after first myocardial infarction. Search for a secular trend. $\mathcal{F A M A} 1982$; 247: 1576-81.

11 Elmfeldt D, Wilhelmsen L, Tibblin G, Vedin JA, Wilhelmsson C, Bengtsson C. Registration of myocardial infarction in the city of Göteborg, Sweden. $\mathcal{F}$ Chronic Dis 1975; 28: 173-86.

12 Elmfeldt D, Wilhelmsen L, Tibblin G, Vedin JA, Wilhelmsson CE, Bengtsson C. A postmyocardial infarction clinic in Göteborg, Sweden. A follow-up of MIpatients in a specialized out-patient clinic. Acta Med
Scand 1975; 197: 497-502.

13 Rose GA, Blackburn H. Cardiovascular survey methods. Geneva: World Health Organisation, 1968: 64.

14 Mantel N. Evaluation of survival data and two new rank order statistics arising in its consideration. Cancer Chem Reports 1966; 50: 163-70.

15 Tarone RE. Tests for trend in life table analysis. Biometrica 1975; 62: 679-82.

16a Jonsell S. A method for determination of the heart size by teleroentgenography (a heart volume index). Acta Radiol (Stockh) 1939; 20: 325-40.

16b Vedin A, Wilhelmsen L, Wedel H, et al. Prediction of cardiovascular deaths and non-fatal reinfarctions after myocardial infarction. Acta Med Scand 1977; 201: 309-16.

17 Cox DR. Regression models and life tables (with discussion). Fournal of the Royal Statistical Society 1972; Series B 34: 187-220.

18 Vedin A, Wilhelmsson C, Elmfeldt D, Säve-Söderbergh J, Tibblin G, Wilhelmsen L. Deaths and nonfatal reinfarctions during two-years follow-up after myocardial infarction. Acta Med Scand 1975; 198: 353-64.

19 Wilhelmsson C, Vedin A, Tibblin G, et al. Registration of myocardial infarction in six Swedish cities during 1973-1977. Acta Med Scand (in press).

20 Hunt D, Sloman G, Christie D, Pennington C. Changing patterns and mortality of acute myocardial infarction in a coronary care unit. $\mathrm{Br}$ Med $\mathcal{F} 1977$; i: 795-8.

21 Norris RM, Caughey DE, Deeming LW, Mercer CJ, Scott PJ. Coronary prognostic index for predicting survival after recovery from acute myocardial infarction. Lancet 1970; ii: $485-8$.

22 Peel AAF, Semple T, Wang I, Lancaster WM, Dall JLG. A coronary prognostic index for grading the severity of infarction. Br Heart $\mathcal{f} 1962 ; 24: 745-60$.

23 Wilhelmsson C, Elmfeldt D, Vedin JA, Tibblin G, Wilhelmsen L. Smoking and myocardial infarction. Lancet 1975; i: 415-20.

24 Wilhelmsson C, Vedin JA, Wilhelmsen L, Tibblin G, Werkö L. Reduction of sudden deaths after myocardial infarction by treatment with alprenolol. Lancet 1974; ii: 1157-60. 